\title{
Effects of Middle East Respiratory Syndrome Coronavirus on post-traumatic stress disorder and burnout among registered nurses in South Korea
}

\author{
Younglee Kim ${ }^{1}$, Eunju $\mathrm{Seo}^{2}$, Youngseon $\mathrm{Seo}^{3}$, Vivien $\mathrm{Dee}^{4}$, Eunhee Hong*5 \\ ${ }^{1}$ Nursing, California State University San Bernardino, California, USA \\ ${ }^{2}$ Nursing, Shinsung University, Chungcheongnam-do, South Korea \\ ${ }^{3}$ Nursing, Eulji University Hospital, Daejeon, South Korea \\ ${ }^{4}$ Nursing, Azusa Pacific University, California, USA \\ ${ }^{5}$ Seoul Women's College of Nursing, Seoul, South Korea
}

Received: April 9, 2018

DOI: $10.5430 /$ ijh.v4n2p27
Accepted: June 3, 2018

Online Published: June 7, 2018

\begin{abstract}
Background: The unprecedented nationwide outbreak of the Middle East Respiratory Syndrome Coronavarius (MERS-CoV) from June to July in 2015 took the Korean healthcare system unexpectedly and created physical and psychological stress and trauma to Registered Nurses unprepared to deal with the viral outbreak.

Purpose: We investigated the effects of Middle East Respiratory Syndrome Coronavirus (MERS-CoV), post-traumatic stress disorder (PTSD) and burnout among Korean registered nurses (RNs).

Methods: A descriptive cross sectional design using a self-administered survey of a convenience sample of 112 Korean RNs. The Impact of Event Scale-Revised-Korean version (IES-R-K) for PTSD and the Maslach Burnout Inventory-Human Services Survey (MBI-HSS) for burnout were utilized.

Results: Overall prevalence for symptoms of PTSD was 50.0\%. PTSD was significantly correlated to burnout $(r=.480, p=$ $.000)$, especially two burnout subscales, emotional exhaustion $(r=.533, p=.000)$, and depersonalization $(r=.497, p=.000)$.

Conclusions: Future anticipatory guidance and management of traumatic outbreak or disaster should be considered for nurses' mental health. Public health and safety at the national level must address quality health outcomes for both patients and healthcare professionals alike.
\end{abstract}

Key Words: Burnout, Korean nurses, Middle East Respiratory Syndrome Coronavirus (MERS-CoV), Post-traumatic stress disorder (PTSD)

\section{INTRODUCTION}

Middle East Respiratory Syndrome Coronavirus (MERS$\mathrm{CoV}$ ) is a viral respiratory infectious disease caused by a novel coronavirus discovered in the Middle East, specifically, Saudi Arabia in 2012. ${ }^{[1]}$ Unlike the severe acute respira- tory syndrome coronavirus (SARS-CoV) which terrorized the whole world in 2003, MERS-CoV occurred mainly in restricted areas like the Middle East. However, an unprecedented nationwide MERS-CoV outbreak occurred in South Korea, the largest outbreak outside of the Middle East dur-

\footnotetext{
*Correspondence: Eunhee Hong, PhD; Email: ehhong@snjc.ac.kr; Address: Seoul Women's College of Nursing, 82 Ganhodae-Ro, Seodaemun-Gu, Seoul, South Korea.
} 
ing the period from May, 2015 to July, 2015 and imposed a huge threat to both public health and safety. This outbreak spread rapidly to 16 healthcare facilities during this period. ${ }^{[2]}$ Choi reported that as of July 20, 2015, there had been 186 laboratory-confirmed MERS-CoV cases including 36 deaths. A total of 136 individuals were recovered from the hospitals, while 14 patients remained. Kim et al. ${ }^{[1]}$ reported that some $44.1 \%$ of the cases were patients exposed in the hospitals through hospital acquired infections, $32.8 \%$ were caregivers and $13.4 \%$ were healthcare personnel.

This unexpected outbreak occurred with one single index case confirmed on May 20, 2015 and the World Health Organization was notified on the same day. The index case was a 68-year-old national of the Republic of Korea with a recent history of travel to four countries in the Middle East. He developed symptoms on May 11 and subsequently sought care at two outpatient clinics and two hospitals creating multiple opportunities for exposure among health care workers and patients. ${ }^{[1,3]}$

As expected, registered nurses ( $\mathrm{RN})$ were the first line responders and care providers during this unprecedented outbreak, and were directly or indirectly exposed to MERS-CoV while caring for these patients. Consequently, the onset of MERS-CoV created a traumatic event in South Korea, and in particular, within the healthcare system. This situation created high anxiety and stress to the point of causing physical and psychological trauma to nurses as health care providers.

\section{LiterATURE REVIEW}

Trauma is defined by the American Psychological Association as the emotional response someone has to an extremely negative event. ${ }^{[4]}$ As mentioned, nurses are on the front line of patient care and are thus, exposed directly or indirectly to negative events such as the care of patients infected with a deadly disease. Following the exposure to such sudden traumatic events, nurses can experience symptoms such as headache, indigestion, stomach upset, tremors in hands, insomnia, nightmare, feeling of unreality and forgetfulness. Although many people who go through traumatic events have difficulty adjusting and coping for a while, they do not have post-traumatic stress disorder (PTSD). It is when these symptoms continue unresolved and last for months or years and interfere with the functioning of daily living, the individual can develop PTSD. ${ }^{[5]}$ Nurses working in clinical sites, typically the emergency room (ER) or intensive care units (ICU) experience mental trauma, with $8.5 \%$ of them developing PTSD due to the frequent mental stress or physical symptoms associated with the care of patients with horrific injuries. ${ }^{[6]}$ Mealer et al. ${ }^{[7]}$ stated that $20 \%$ of nurses in ICU showed similar symptoms of mental disorders and typically $30 \%$ of them showed feelings of depression. Additionally, stress levels among nurses in operating room (OR) were often higher when they cared for patients with external traumatic wounds. ${ }^{[8]}$ This may imply that nurses can incur tremendous mental stress when asked to make rapid and accurate judgments for urgent and serious situations, all the while worrying about being exposed to serious physical illnesses themselves. Experiencing consistent and continuous stress can lead to psychological health problems like PTSD and cause physical and/or emotional exhaustion referred to as burnout.

Burnout is a negative experience among people who lack the psychological and physical resources to meet demands and expectations on the job. ${ }^{[9]}$ It is defined as personal reactions to chronic emotional stress in numerous direct or indirect interactions among people. ${ }^{[10]}$ Burnout in the working unit has increased over the past decade. ${ }^{[11]}$ It has become a major concern for the nursing profession because burnout has caused physical and psychological exhaustion for nurses to the extent of disturbing their clinical thinking and decision making as a healthcare provider. ${ }^{[12]}$ It can have a significant impact on patients' outcomes, increased mortality and failure to rescue ${ }^{[13]}$ and patient dissatisfaction. ${ }^{[14]}$

Moreover, it can be related to nurse shortages in diverse clinical settings. ${ }^{[15-17]}$ Burnout has a wide range of symptoms; ${ }^{[17]}$ however, it can be conceptualized into three categories: emotional exhaustion (EE), depersonalization (DP), and reduced personal accomplishment (PA). ${ }^{[18]}$ Emotional exhaustion refers to feelings of being overwhelmed; depersonalization is defined as impersonal feelings that seem unreal or not belonging to oneself; while reduced personal accomplishment means a lack of self-achievement. ${ }^{[19]}$ Moreover, PTSD and burnout can be psychological stressors that cause the development of pessimistic or negative feelings of depression or anxiety, resulting in poor relationships with others like family, friends, or colleagues in life. ${ }^{[20,21]}$ The co-existence of PTSD and burnout has a dramatic effect on work and non-work related activities and perception. ${ }^{[19]}$ The purpose of our study was to investigate the effects of MERS$\mathrm{CoV}$ on symptoms of PTSD and burnout among Korean registered nurses (RN) working in ER, ICU, and OR during the MERS-CoV outbreak in South Korea.

\section{Methods}

\subsection{Study setting}

Our study was conducted at a 300-bed university affiliated teaching hospital in South Korea. The study hospital was identified as one of 16 hospitals impacted by the MERS-CoV outbreak from June, 2015 to July, 2015, and the nursing care units were ER, ICU, and OR. 


\subsection{Study design and participants}

We used a descriptive cross-sectional design. One hundred fifteen (115) RNs participated. There were no self-report by the participants of having mental illness history; however, three RNs did not complete the survey questionnaires and were excluded from the study which resulted in a convenience sample of 112 RNs. All study participants were Koreans and spoke and wrote in the Korean language. The required sample size was 110 participants based on $\mathrm{G}$ power program 3.1 with alpha of .05 , power of .80 , the effect size of .30 .

\subsection{Data collection and ethical considerations}

Institutional review board application: IRB No. 2015-06004-001 was approved at E hospital in South Korea. Data collection commenced from June 30, 2015 to July 10, 2015. After research information on study purpose and procedures were provided by our study team, the participants provided their written consents and completed a self-administered survey. Participants also received information on PTSD following the survey.

\subsection{Variables and instruments}

\subsubsection{Sociodemographic and work history}

Sociodemographic characteristics included the participants gender, age, marital status, education, and religion. Work history included: job position (charge or head nurse/general nurse) working unit (ER, ICU, or OR), years of working experience as $\mathrm{RN}$, and position held in their working units.

\subsubsection{PTSD measured by The Impact of Event Scale (IES)}

IES was first developed by Horowitz et al., in 1979 for PTSD with 15-question items. ${ }^{[22]}$ However, Weiss and Marmar ${ }^{[23]}$ added seven items to the IES-R(revised version) which were related to the hyperarousal symptoms of PTSD measuring personal reflecting, awakening, avoidance, invasion, sleep disorders, mental paralysis, and dissociation. IES-R is a 5-point Likert scale to answer how often these symptoms appeared in the last one month. The scores of the PTSD range from 0 to 88 . The maximum score of 88 indicates a severe depressed condition which requires urgent medical attention and further assessment. Eun et al. ${ }^{[24]}$ performed a study on reliability and validity of the IES-R-K (Korean version) and found that 24 or 25 was an optimal cut-off score for the Korean population. Lim et al. ${ }^{[25]}$ also performed a reliability and validity study on IES-R-K with Cronbach $\alpha$ coefficients ranged of .91 to .93 . For our study, we used the IES-R-K version by Lim and colleagues ${ }^{[25]}$ and a cut-off score of 25 suggested by Eun et al. ${ }^{[24]}$ In our study the Cronbach's alpha coefficient of IES-R-K was 94 .

\subsubsection{Burnout measured by Maslach Burnout Inventory- Human Services Survey (MBI-HSS)}

The Maslach Burnout Inventory-Human Services Survey (MBI-HSS) is a screening tool developed by Maslach and Jackson in 1981 to measure personal perceived burnout. It was translated and validated by Choi and Chung ${ }^{[26]}$ for Korean participants. The MBI-HSS consisted of a 22 -item survey with a 7-point Likert scale. This tool has three subcategories: 9 items of EE, 5 items of DP, and 8 items of PA. An answer can range from never $=0$ to every day $=6$; thus EE, DP, and PA range from 0-54, 0-30, and 0-48. Higher scores mean more burnout. The Cronbach's $\alpha$ for the MBI ranged from .76 to $.87 .^{[26,27]}$ In our study the Cronbach's $\alpha$ was .84 .

\subsection{Statistical analysis}

Data was analyzed using the Statistical Package for the Social Sciences (SPSS) 24 version. Uncompleted questionnaires were excluded from analysis. Descriptive statistics was performed to understand the sociodemographic characteristics and work history of study participants. Participants' age was categorized into two groups: ages 18-30 years (younger group) and 31-42 years (older group).

Prevalence for symptoms of PTSD and calculating the mean scores differences among the ER, ICU, and OR units were performed by analysis of variance (ANOVA). In addition, the mean differences of the burnout among the ER, ICU, and OR units were also calculated by ANOVA. Based on the results of the IES-R-K, study participants were categorized as low PTSD risk (0-24) and high PTSD risk (25-88). To measure statistical associations of the sociodemographic characteristics and working history, six factors such as age, marital status, education, working unit (ER, ICU, or OR), religion, and years of working experience as $\mathrm{RN}$ were selected. To find significant associations between symptoms for PTSD and the sociodemographic and work history variables, Chi-square was performed by using the dichotomized groups. The $t$-test and ANOVA were also used to show the relationships between the sociodemographic, working history and burnout including three subcategories (EP, DP, and PA). Lastly, Pearson correlation coefficient was performed to verify significant correlations among the total score of PTSD and the total score of burnout, burnout-EP, burnout-DP, and burnout-PA.

\section{Results}

The sociodemographic characteristics and work history of our participants are shown in Table 1 . The age range of the 112 participants was between 22 and 42 years and the mean age was $28.70(\mathrm{SD}=4.43)$. In our study, 99 participants $(88.3 \%)$ were women whereas 13 participants (11.6\%) 
were men. Ninety five $(84.8 \%)$ were not married and 17 $(15.1 \%)$ were married. In the education category, 65 participants $(58.0 \%)$ completed a bachelor's degree in nursing. Fifty eight participants $(51.8 \%)$ reported that they had no religious affiliation. Their working areas were ER $(n=30$, $26.8 \%)$, ICU ( $\mathrm{n}=51,45.5 \%)$, and OR $(\mathrm{n}=31,27.7 \%)$. All study participants had at least 6 months of RN work experience. The average years of working experience as an RN was 4.87 years $(\mathrm{SD}=4.28)$. One hundred and three participants $(92.0 \%)$ work as general nurses while seven $(6.0 \%)$ were charge nurses in their working units.

Table 1. Descriptive statistics of the variables in the sample $(\mathrm{N}=112)$

\begin{tabular}{|c|c|c|}
\hline Variables (Mean \pm SD) & $\mathbf{n}$ & $\%$ \\
\hline \multicolumn{3}{|l|}{ Gender } \\
\hline Male & 13 & 11.6 \\
\hline Female & 99 & 88.4 \\
\hline \multicolumn{3}{|l|}{ Age $(28.70 \pm 4.43)$} \\
\hline $18-30$ & 65 & 58.0 \\
\hline $31-42$ & 47 & 42.0 \\
\hline \multicolumn{3}{|l|}{ Marital status } \\
\hline Married & 17 & 15.2 \\
\hline Unmarried & 95 & 84.8 \\
\hline \multicolumn{3}{|l|}{ Education } \\
\hline Associate degree & 28 & 25.0 \\
\hline Bachelor degree & 65 & 58.0 \\
\hline Master degree & 19 & 17.0 \\
\hline \multicolumn{3}{|l|}{ Religion } \\
\hline Catholic & 10 & 8.9 \\
\hline Protestant & 29 & 25.5 \\
\hline Buddhist & 11 & 9.8 \\
\hline Others & 4 & 3.6 \\
\hline No religion & 58 & 51.8 \\
\hline \multicolumn{3}{|l|}{ Working unit } \\
\hline ER & 30 & 26.8 \\
\hline ICU & 51 & 45.5 \\
\hline OR & 31 & 27.7 \\
\hline \multicolumn{3}{|l|}{ Working shift } \\
\hline 3 shifts $(\mathrm{D} / \mathrm{E} / \mathrm{N})$ & 80 & 71.4 \\
\hline 2 shifts $(\mathrm{D} / \mathrm{E})$ & 15 & 13.4 \\
\hline 1 shift (D) & 17 & 15.2 \\
\hline \multicolumn{3}{|c|}{ Working experience as a $\mathrm{RN}(4.87 \pm 4.28)$} \\
\hline$<5$ years & 66 & 58.9 \\
\hline 5 - 10 years & 33 & 29.5 \\
\hline $10<$ & 13 & 11.6 \\
\hline \multicolumn{3}{|l|}{ Job position } \\
\hline General-duty RN & 103 & 92.0 \\
\hline Charge RN & 7 & 6.3 \\
\hline Head RN & 2 & 1.8 \\
\hline
\end{tabular}

Note. D; day, E; evening, $\mathrm{N}$; night, ER; emergency room, ICU; intensive care unit, OR; operation room, RN; registered nurse

Overall prevalence for PTSD symptoms using IES-R-K was 30
$50.0 \%$ in our sample with ER $(60.0 \%)$, ICU (43.0\%), and OR $(51.6 \%)$ respectively. The mean scores for symptoms of PTSD were $26.63(\mathrm{SD}=12.96)$ at ER, $23.96(\mathrm{SD}=14.21)$ at ICU, and $25.64(\mathrm{SD}=16.81)$ at OR. Our study also investigated the score differences for symptoms of PTSD among the three units: ER, ICU, and OR. However, there were no significant differences of the individual perception of the PTSD in our sample. The total score for burnout was 65.10 $(\mathrm{SD}=9.44)$ with ER, $65.63(\mathrm{SD}=7.39), \mathrm{ICU}, 65.12(\mathrm{SD}=$ $9.62)$, and $\mathrm{OR}, 64.58(\mathrm{SD}=11.10)$ respectively. There were no score differences of burnout among the ER, ICU, and OR.

According to the results of Chi-square with the dichotomized groups, there were no significant associations between symptoms of PTSD and the sociodemographic and work history variables. In addition, the results of $t$-test and ANOVA also showed no significant associations between burnout and the sociodemographic and work history variables. Instead, the Pearson correlation coefficient test showed that the PTSD was significantly correlated to burnout $(r=.480, p=.000)$, in particular, emotional exhaustion $(r=.533, p=.000)$, and depersonalization $(r=.497, p=.000)$ (see Table 2).

\section{DiscuSSION}

In our sample, the overall rate of PTSD symptoms by MERS$\mathrm{CoV}$ in 2015 was $50.0 \%$ with $\mathrm{ER}$ at $60.0 \%$, the highest among the three units (ER, ICU, and OR). Ben-Ezra et al. ${ }^{[28]}$ reported that PTSD rates were $10.5 \%$ in physicians and $35.7 \%$ of nurses after the war between Lebanon and Israel erupted. Mealer et al. ${ }^{[19]}$ also found that the prevalence of PTSD among nurses employed at a tertiary care level II trauma facility at a hospital in the USA was $18 \%$. Lavoie et al. ${ }^{[29]}$ reported that ER nurses experienced symptoms of PTSD more than the nurses in ICU or general medicine floor in the sample of 12 nurses in Quebec, Canada. Adriaenssens et al. ${ }^{[30]}$ reported that among 248 ER nurses, more than $30.0 \%$ had subclinical levels of anxiety, depression, and somatic complaints and even $8.5 \%$ of them suffered from clinical levels of PTSD due to traumatizing events resulting from the provision of nursing care. In the sample of 363 Korean ER nurses in 23 emergency medical centers in South Korea, 130 ER nurses (35.8\%) were in the high risk for symptoms of PTSD using the IES-R-K screening tool. ${ }^{[31]}$ Likewise, Mealer and colleagues ${ }^{[32]}$ identified that the prevalence of symptoms of PTSD in ICU $(24.0 \%)$ was relatively higher than that of the general units $(14.0 \%)$ and that OR nurse suffered from severe job stress which reduced their constructive stress coping strategies. ${ }^{[33]}$ In our sample, the PTSD symptom prevalence was $50.0 \%$ and higher than noted in the above published studies. Clearly, our study participants from the ER, ICU, and OR had experienced PTSD symptoms during the MERS-CoV outbreak in 2015. 
Table 2. Intercorrelations among the study variables $(\mathrm{N}=112)$

\begin{tabular}{llllll}
\hline & Total PTSD & Total burnout & Burnout-EE & Burnout-DP & Burnout-PA \\
\hline Total PTSD & 1 & & & & \\
Total burnout & $480^{* *}$ & 1 & & & \\
Burnout-EE & $.533^{* *}$ & $.857^{* *}$ & 1 & 1 & \\
Burnout-DP & $.497^{* *}$ & $.746^{* *}$ & $.626^{* *}$ & -.086 & 1 \\
Burnout-PA & -.068 & $.370^{* *}$ & -.049 & \\
\hline
\end{tabular}

Note. PTSD; Posttraumatic stress disorder, EE; Emotional Exhaustion, DP; Depersonalization, PA: Personal accomplishment; ** $p<.01$ (2-tailed)

After the outbreak of MERS-CoV, the Korean government developed the Disaster Emergency Medical Preparedness and Response Manual (DEMPRM) to systematically prepare and respond to future disaster or outbreak in cooperation with nearby hospitals and communities. ${ }^{[34]}$ The DEMPRM specifically addresses the physical and psychological management of patients during and after a disaster such as MERS-CoV. However, this manual lacks specification on the management of mental stress associated with PTSD for healthcare providers. The lack of appropriate intervention or treatment for PTSD symptoms can lead to problems with individual social, educational, and occupational functioning; furthermore, it can threaten life and impair job performance. ${ }^{[21]}$ Therefore, our study findings highlight the need for appropriate MERS-CoV treatments for healthcare professionals.

We did not find significant associations between the sociodemographic/work history factors and symptoms of PTSD during the MERS-CoV outbreak in our study. On the other hand, Han and $\mathrm{Yoo}^{[31]}$ found that education $(\mathrm{F}=5.058, p<.01)$, clinical experience $(\mathrm{F}=3.167, p<.05)$, voluntary choice of ER deployment $(t=-2.948, p<.01)$ and desire for ER deployment $(\mathrm{F}=-2.948, p<.01)$ were the risk factors for symptoms of PTSD in the sample of Korean ER nurses in 2015. We also found no significant association between sociodemographic/work history factors and symptoms of burnout in our study. However, Kim and Choi ${ }^{[35]}$ found that high job stress $(\beta=.59, p<.001)$, poor support from family and friends $(\beta$ $=-0.14, p<.05)$, and poor hospital resources $(\beta=-0.19, p<$ .001 ) were the significant risk factors for nurses' burnout in a Korean study during the outbreak of MERS-CoV in 2015. Our study focused on the sociodemographic factors, such as: age, marital status, education, working unit, religion, and years of working experience as an RN; however, we anticipate that for future research, factors such as social support, job stress, or available resources/treatments for outbreak at work should be considered.

We also found no significant associations between the sociodemographic/work history factors and the subcategories of burnout (EE, EP, and PA). Queiros et al. ${ }^{[36]}$ reported that
DP was related to individual age and gender while job rank (senior or junior) and length of working experience were significantly associated with poor sense of PA. In other studies, EE was associated with age and education level ${ }^{[37]}$ and unmarried nurses had high scores of EE and DP and low score of PA. ${ }^{[16]}$ Ang et al. ${ }^{[15]}$ also found that age, job rank, and neuroticism were significantly related to EE, DP, and PA.

Instead, we found that PTSD was significantly associated with burnout. According to Meadors et al. ${ }^{[38]}$ in a sample of 167 nurses from pediatric intensive care unit (PICU), neonaal intensive care unit (NICU), and/or pediatric unit (PEDS) in the United States, the symptoms of PTSD were significantly correlated with burnout $(r=.48, p<.01)$. From a systematic review of determinants for burnout among emergency nurses from 1989 to 2014, Adriaenssens et al. ${ }^{[30]}$ reported that the symptoms of PTSD were significantly related to burnout. In particular, not only symptoms of PTSD among health providers had significant association with their own health outcomes, ${ }^{[14,39]}$ symptoms of PTSD also disrupt their critical thinking process to determine and perform professional care activities. Critical thinking is essential to recognize problems and perform appropriate nursing care for health outcomes. ${ }^{[40]}$ Consequently, the RNs with symptoms of PTSD in our sample could have difficulty performing their critical thinking process to provide quality healthcare for the patients at the hospital during the MERS-CoV outbreak.

Because our study collected data from only one of 16 hospitals for the patients with MERS-CoV in South Korea during the outbreak in 2015, our sample cannot fully represent all Korean nurses' characteristics. In addition, our study focused on the effects of MERS-CoV on PTSD among RNs working in the ER, ICU and OR. In the future, a comparative design study should be developed to investigate associations of healthcare providers' PTSD or burnout due to disaster/outbreak between and among ER, ICU, and OR with other patient care units. Since we only collected quantitative data of the nurses' PTSD or burnout during this unpredictable disaster/outbreak like the MERS-CoV, our study could be 
enhanced by conducting a mixed method study to include a qualitative design to understand RNs' personal experiences in greater depth.

\section{Conclusions}

Nurses often stand at the forefront of a dangerous scene and face traumatic problems during an outbreak or disaster. Nurses may experience symptoms of PTSD and burnout while taking care of patients during an outbreak or disaster. Public health and safety on the national and international stage must address quality health outcomes for both patients and nurses alike. Healthcare providers' mental health should be considered in future anticipatory guidance on disaster preparation at the government or community level.

\section{CONFlicts OF InTEREST Disclosure}

The authors declare no conflicts of interest.

\section{REFERENCES}

[1] Kim SW, Yang TU, Jeong Y, et al. Middle East Respiratory Syndrome Coronavirus outbreak in Republic of Korea. Osong Public Health Research Perspective. 2015; 6(1): 269-278.

[2] Choi JY. An Outbreak of Middle East Respiratory Syndrome Coronavirus Infection in South Korea, 2015. Yonsei Medical Journal. 2015; 56(5): 1174-1176. PMid:26256957. https://doi.org/10.3349/ ymj . 2015.56.5.1174

[3] Cho SY, Kang JM, Ha YE, et al. MERS-CoV outbreak following a single patient exposure in an emergency room in South Korea: an epidemiological outbreak study. The Lancet. 2016; 388(10048): 994 1001. https ://doi .org/10.1016/S0140-6736 (16) 30623-7

[4] American Psychological Association Trauma 2016 [Web log post]. Available from: http://www.apa.org/topics/trauma/index. aspx

[5] Friedman MJ, Resick PA, Bryant RA, et al. Considering PTSD for DSM-5. Depress and Anxiety. 2011; 28(9): 750-769. PMid:21910184. https://doi.org/10.1002/da.20767

[6] Cohen SS, Mulvaney K. Field observations: Disaster medical assistance team response for hurricane charley, Punta Gorda, Florida, August 2004. Disaster Management \& Response. 2005; 3(1): 22-27. PMid:15627127. https://doi.org/10.1016/j.dmr.2004.10. 003

[7] Mealer M, Jones J, Newman J, et al. The presence of resilience is associated with a healthier psychological profile in intensive care unit (ICU) nurses: Results of a national survey. International Journal of Nursing Studies. 2012; 49(3): 292-299. PMid:21974793. https://doi.org/10.1016/j.ijnurstu. 2011.09.015

[8] Park AS, Cho YC. Factors related to psychosocial stress and fatigue symptom among nurses working at ward and operating room in University hospitals. Journal of the Korea Academia-Industrial Cooperation Society. 2013; 14(4): 1781-1791. https://doi.org/ 10.5762/KAIS. 2013.14.4.1781

[9] Maslach C, Leiter MP. Early predictors of job burnout and engagement. Journal of Applied Psychology. 2008; 93(3): 498-512. https://doi.org/10.1037/0021-9010.93.3.498

[10] Maslach C, Schaufeli WB, Leiter MP. Job burnout. Annual Review of Psychology. 2001; 52(1): 397-422. PMid:11148311. https : //doi.org/10.1146/annurev.psych.52.1.397

[11] Ca-adas-De la Fuente GA, Vargas C, San Luis C, et al. Risk factors and prevalence of burnout syndrome in the nursing profession. International Journal of Nursing Studies. 2015; 52(1): 240-249. PMid:25062805. https://doi.org/10.1016/j.ijnurstu. 201 4.07 .001

[12] Rajeswari H, Sreelekha B. Burnout among nurses. International Journal of Scientific Research. 2015; 4(8): 407-410. Available from: https://www. worldwidejournals.com/international-j ournal-of-scientific-research-(IJSR)/articles.php $? \mathrm{val}=\mathrm{Nj}$ I $\mathrm{wOA}==\& \mathrm{~b} 1=753 \& \mathrm{k}=189$

[13] Halm M, Peterson M, Kandels M, et al. Hospital nurse staffing and patient mortality, emotional exhaustion, and job dissatisfaction. Clinical Nurse Specialist: The Journal for Advanced Nursing Practice. 2005; 19(5): 241-254. PMid:16179855. https://doi.org/10.1 097/00002800-200509000-00007

[14] Vahey DC, Aiken LH, Sloane DM, et al. Nurse burnout and patient satisfaction. Medical Care. 2004; 42(2): 57-66. https : //doi.org/ 10.1097/01.mlr.0000109126.50398.5a

[15] Ang SY, Dhaliwal SS, Ayre TC, et al. Demographics and personality factors associated with burnout among nurses in a Singapore tertiary hospital. Biomedical Research International. 2016; 1-12. PMid:27478835. https://doi.org/10.1155/2016/6960184

[16] Lee HF, Yen M, Fetzer S, et al. Predictors of burnout among nurses in Taiwan. Community Mental Health Journal. 2015; 51(6): 733737. PMid:25536942. https ://doi .org/10.1007/s10597-014 $-9818-4$

[17] PubMed Health. Depression: What is burnout? 2017. Available from: https://www.ncbi.nlm.nih.gov/pubmedhealth/PMHO 072470/

[18] Maslach C, Jackson S. Burnout in health professions: a social psychological analysis 1982. Edited by Sanders G., Suls JM. Social psychology of health and illness. Lawrence Eribaum Associates Inc. Hillsdale, New Jersey. 1982; 227-254.

[19] Mealer M, Burnham EL, Goode CJ, et al. The prevalence and impact of post-traumatic stress disorder and burnout syndrome in nurses. Depression and Anxiety. 2009; 26(12): 1118-1126. PMid:19918928. https://doi.org/10.1002/da.20631

[20] Emergency public health. PTSD in Emergency Workers. 2014. Available from: https://emergencypublichealth.net/2014/07/ $14 / \mathrm{ptsd} /$

[21] National Collaborating Centre for Mental Health. Post-Traumatic Stress Disorder: The Management of PTSD in adults and children in primary and secondary care. Leicester (UK): Gaskell; (NICE Clinical Guidelines, No. 26.) 2, Post-traumatic stress disorder 2005. Available from: https://www.ncbi.nlm.nih.gov/books/NBK56506/

[22] Horowitz M, Wilner N, Alvarez W. Impact of Event Scale: a measure of subjective stress. Psychosomatic Medicine. 1979; 41(3): 209218. PMid:472086. https://doi.org/10.1097/00006842-197 905000-00004

[23] Weiss DS, Marmar CR. The Impact of Event Scale-Revised 1997. Edited by Wilson JP, Keane TM. Assessing Psychological Trauma and PTSD. New York: Guilford Press; 1997. 399-411 p. 
[24] Eun HJ, Kwon TW, Lee SM, et al. A study on reliability and validity of the Korean version of impact of event scale-revised. Journal of Korean Neuropsychiatric Association. 2005; 44(3): 303-310.

[25] Lim H, Woo J, Kim T, et al. Reliability and validity of the Korean version of the Impact of Event Scale-Revised. Comprehensive Psychiatry. 2009; 50(4): 385-390. PMid:19486738. https: //doi.org/10.1016/j.comppsych.2008.09.011

[26] Choi HY, Chung NW. Perfectionism tendency, social support, and burnout among counselors. Korean Journal of Health Psychology. 2003; 8(2): 279-300.

[27] Maslach C, Jackson SE. The measurement of experienced burnout. Journal of Organizational Behavior. 1981; 2(2): 99-113. https: //doi.org/10.1002/job.4030020205

[28] Ben-Ezra M, Palgi Y, Essar N. Impact of war stress on post-traumatic stress symptoms in hospital personnel. General Hospital Psychiatry. 2007; 29(3): 264-266. PMid:17484945. https://doi.org/10.1 016/j .genhosppsych. 2007.03.001

[29] Lavoie S, Talbot LR, Mathieu L. Post-traumatic stress disorder symptoms among emergency nurses: their perspective and a "tailor-made" solution. Journal of Advanced Nursing. 2011; 67(7): 1514-1522. PMid:21323975. https://doi.org/10.1111/j.1365-2648.20 10.05584. $\mathrm{x}$

[30] Adriaenssens J, De Gucht V, Maes S. The impact of traumatic events on emergency room nurses: Findings from a questionnaire survey. International Journal of Nursing Studies. 2012; 49(11): 1411-1422. PMid:22871313. https://doi.org/10.1016/j.ijnurstu. 201 2.07 .003

[31] Han KA, Yoo EK. Experience of the Nurses in Emergency Room to the Traumatic Event and Posttraumatic Stress Disorder. Advanced Science and Technology Letters. 2016; 128(1): 247-250. https://doi.org/10.14257/astl.2016.128.49

[32] Mealer M, Shelton A, Berg B, et al. Increased prevalence of posttraumatic stress disorder symptoms in critical care nurses. American Journal of Respiratory and Critical Care Medicine. 2007; 175(7): 693-697. PMid:17185650. https://doi.org/10.1164/rccm.2 00606-7350C
[33] Chen CK, Lin C, Wang SH, et al. A study of job stress, stress coping strategies, and job satisfaction for nurses working in middle-level hospital operating rooms. Journal of Nursing Research. 2009; 17(3): 199-211. PMid:19738448. https://doi.org/10.1097/JNR.0b 013e3181b2557b

[34] Ministry of Health and Welfare. Disaster Emergency Medical Emergency Response Manual 2016. [Web log post]. Available from: http://www .mohw.go.kr/front_new/jb/sjb0406vw.jsp?PA R_MENU_ID $=03 \& M E N U$ ID $=030406 \& C O N T$ _SEQ $=329536 \&$ page $=1$

[35] Kim JS, Choi J. Factors influencing emergency nurses' burnout during an outbreak of Middle East Respiratory Syndrome Coronavirus in Korea. Asian Nursing Research. 2016; 10(4): 295-299. PMid:28057317. https://doi.org/10.1016/j .anr.2016.10. 002

[36] Queiros C, Carlotto MS, Kaiseler M, et al. Predictors of burnout among nurses: An interactionist approach. Psicothema. 2013; 25(3): 330-335. PMid:23910747.

[37] Wu FQ, Wang YL, Wu Y, et al. Competency standard education in the training of nursing undergraduates. International Journal of Nursing Sciences. 2014; 1(4): 367-37. https://doi.org/10.1016/j.ij nss. 2014.10 .010

[38] Meadors P, Lamson A, Swanson M, et al. Secondary traumatization in pediatric healthcare providers: Compassion fatigue, burnout, and secondary traumatic stress. Omega: Journal of Death And Dying. 2009; 60(2): 103-128. PMid:20222232. https://doi.org/10.2 190/OM.60.2.a

[39] Bittner N, Gravlin G. Critical thinking, delegation, and missed care in nursing practice. Journal of Nursing Administration. 2009; 39(3): 142-146. PMid:19590471. https://doi.org/10.1097/NNA.0b $013 \mathrm{e} 31819894 \mathrm{~b} 7$

[40] Papathanasious IV, Kleisiaris CF, Fradelos EC, et al. Critical thinking: the development of an essential skill for nursing students. Acta Informatica Medica. 2014; 22(4): 283-286. PMid:25395733. https://doi.org/10.5455/aim.2014.22.283-286 